\title{
GRISIM: A Partnership in Nursing Research
}

In this issue, we feature the second in a series of nursing research unit profiles with an interview with Drs. Sylvie Cossett and Celeste Johnston, Co-Directors of the Groupe de recherche interuniversitaire en sciences infirmières de Montréal (GRISIM). GRISIM was formed in April 2003 as a partnership between nurse researchers in the School of Nursing at McGill University and Faculty of Nursing at the University of Montreal. GRISIM's 25 members, drawn from the two nursing faculties, focus specifically on the development and evaluation of nursing interventions and the measurement of their impact on patient populations.

Sylvie Cossette (SC) finished her PhD in nursing at McGill in 2000, and is an associate professor at the Faculty of Nursing at the University of Montreal. Since 2002, she has also run a research program which is based in the Montreal Heart Institute focusing on how to assist cardiac patients when they return home from hospital after an MI or any cardiac event.

Celeste Johnston (CJ) is a professor at the School of Nursing at McGill University since 1988, and before that was in practice at the Montreal Children's Hospital. Her research is in the area of pain, particularly pain in neonates. She has recently initiated a focus on research into knowledge translation.

\section{DP: What led to the development of the GRISIM unit?}

CJ: There were several factors that came together at the same time. First of all, it is important to know that the University of Montreal and McGill had worked 
together on a joint $\mathrm{PhD}$ program. This had waxed and waned in terms of how much collaboration there was and had been going back into the waning phase. However, there was a building-up phase again when the FRSQ [Fonds de recherche en santé du Québec], along with the Newton Foundation, indicated that they would be willing to entertain a proposal from the two universities for nursing research. It was fortuitous that all these things came together at the same time. We put together a proposal and decided from the beginning, because there was also money for knowledge translation and research and health services research from the Canadian Health Services Research Foundation to sustain research activity in these areas, that we would concentrate specifically on nursing intervention research.

\section{DP: How did you arrive at that decision? What process did you use to reach that focus?}

CJ: Many of us who were not part of the health services research group FERASI [Formation et expertise en recherche en administration des services infirmiers] - for example, the University of Montreal, McGill and Laval - felt the need to develop specific nursing knowledge that could then be translated into interventions with clinical outcomes.

SC: At that time, in Montreal there was very little theoretical research, very little research on intervention, because it is expensive to do and there were few academics and student researchers beginning their work in nursing interventions.

CJ: It was hard for people, for example, to get pilot money to do a study before submitting it to the big agencies. As you know, each year the competition at the Canadian Institutes of Health Research is getting stronger, and FRSQ, that had funded a lot of us for intervention research at one point, was cutting back on operating grants. Instead, they were using their money for groups, teams and individual research career awards, and they wanted people to go outside for the operating grant money. So for those reasons, intervention research was an orphan in terms of the funding. Also, we felt we were at the point in research that we could move beyond the descriptions and begin those kinds of studies.

\section{DP: Can you talk about your funding and what it allows you to do?}

CJ: There are several players in the funding. First there is the FRSQ, which reviewed GRISIM. (Some of their money actually comes from the Ministry of Health and Social Services.) We also receive funding from the Newton Foundation. The University of Montreal and McGill give us money specifically for student fellowships. We also are in partnership with the Canadian Nurses Foundation for student projects. CHUM provides the building we're housed in, and it actually belongs to the University of Montreal teaching hospital. Money for the furniture came from the McGill University Health Sciences Centre. 
The FRSQ and the Newton funds are essentially for overhead, operating funds, funds to pay our staff research assistants, the coordinator, the administrative assistant. We've hired a part-time statistician and a part-time editor, who are paid out of operating funds. We also use that money for bursaries for the students on all levels from undergraduate to post-doc to encourage them to do a project as part of a course that Sylvie teaches at the University of Montreal and at McGill on nursing intervention research.

We also have the pilot project money for the investigators to run a pilot study, to develop a measure, to test a measure, to test the feasibility and so on. It's funding for investigators to conduct preliminary work before they submit externally. I should mention we've had two recent successes. Nancy Feeley and Josée Côté both had pilot money from us and went on to get money from the clinical trials committee of CIHR.

Then, the final bit of money is for student projects, because we find that students have great ideas and want to do their research project but their supervisor may or may not have the money to support them. So we have money for those student projects through the partnership with the Centre for Nursing Studies.

SC: And most of the fellowships are for the PhD students and also for pre-assessing their research projects.

CJ: We are often looking for graduate students. It's very difficult to get bright nurses in good clinical positions to leave those positions and come back to school. So we see this as a motivation to help them come back. They're allowed to top up the fellowships as well, so it's not as if they can't have anything else if they take this. So some of our PhD students are bringing in bursaries [that amount to] almost as much as they would earn as a salary.

\section{DP: What about leadership - essentially, the roles that you play in GRISIM. How would you describe your leadership style, and how is GRISIM led by you both?}

CJ: Well, it's sort of like herding cats. It's setting up the environment in such a way that people feel that they are getting something out of it, and that they will want to participate in it so that it becomes synergistic. I lead by trying to meet the needs of the researchers and encouraging them to contribute, because there's a lot of collective intelligence in the group and creativity. As a leader, I work to maximize that, so it's not leading in the traditional way.

SC: I would say we have set up things to help people to get together, activities, groups and events between the faculties of McGill and Montreal. 
CJ: We have come up with a theoretical idea of axes; this was developed based on trying to be very inclusive with people. We, as leaders, tried to say, "Okay, we know this person works in cardiac adults, we know this person works in neonates and maternal-child interactions and this person works in international health, but how can we create something that can bring everybody together?" It worked moderately well for the students, but not for researchers. Everybody was still doing his/her own thing. But we held a strategic planning meeting where ideas were generated from the faculty, including the adjunct faculty, and we came up with four teams that are working on developing the science of nursing intervention. Not everybody is participating, but the people that are, are really into it: they're committed, there's lots of progress being made. There's a real excitement about the kinds of projects that they're working on, and not all of it is population specific. It's all about the science of doing nursing intervention research.

\section{DP: Given that leading researchers is a bit like herding cats, what do the researchers get out of it? Why do they allow themselves to be herded to the extent that they are within GRISIM?}

SC: One thing that is important is to have an output for the researcher. Everybody is engaged in their own careers, so we have to have some reward or input to help them to progress. One of the things we have done is to organize, for example, seminars where experts or advisers are invited to talk about the topic each group is working on to help them set up either their grant proposal or a paper they are preparing. Another output is that each group is working on a specific paper, developing or evaluating an intervention. The other things that are rewarding are the grants and fellowships that their students can have. It's a very important part, because all the PhD students have problems getting funding for their $\mathrm{PhD}$ and intervention research; so it's another advantage that their supervisors have in participating with GRISIM.

CJ: We've only just started to see this, but there's potentially the use of the expertise within GRISIM for informal consultation. Some of the more junior researchers are now asking the more senior researchers to review their proposals; they'll discuss their proposal to get ideas about what they can do to modify it so that it'll be stronger when it goes in. We'd like to see more of that. I think the students probably get more out of it than the faculty, but that, in turn, is reinforcing for the faculty if they feel their students are getting something out of it.

SC: We also have clinicians in GRISIM, and one of the things they ask for is networking between centres, because they did not know what others were doing in different centres. By meeting here, they can exchange among themselves and not reinvent the wheel all the time. 


\section{DP: How did you figure out your leadership - the way you were going to lead GRISIM?}

CJ: It was trial and error. We have a whole range of people. We have brand new faculty and we have very senior researchers. So the traditional way of leading isn't going to work. The whole point we wanted was to have the synergy of the members. We never asked the question, "How can we be good leaders?" We just asked, "What is it that this group needs to develop, and how can we capitalize on the fact that these are two university schools of nursing in the same city?" What can we do to facilitate that collaboration and improve excellence - the whole is greater than the sum of the parts idea. We thought of ourselves more as facilitators than leaders.

\section{DP: Let's spend a bit of time on the nursing, as opposed to the interdiscipli- nary, focus. How do you sort that out in GRISIM?}

CJ: There's been a lot of discussion about that, and it's a tricky balance because on the one hand we wanted it clear that the focus was on nursing intervention. Part of the case we made to the FRSQ was that nursing intervention has an impact on the health of the population, which we believe very firmly. Now all of us collaborate with people in other disciplines - either they are co-investigators on our grants, or we're co-investigators on theirs or both. We very much appreciate that probably the very best intervention or clinical research is going to be multidisciplinary, but at the same time, we wanted to keep it focused on nursing. We started off with just nursing faculty members, and you still need to be a full member of the faculty of one of the two universities to be a full member of GRISIM, but we have created a category of adjunct researchers, who may be nurses from outside those places or somebody from another discipline. We're slowly adding people from other disciplines.

We also use non-GRISIM researchers as part of the scientific evaluation committee to judge the proposals that come in, partly because we need people, and if they are members of GRISIM they're in conflict. Then we're moving some of these people to adjunct membership. It's a slow process, and that's partly intentional, because we want to be very well established about what it is that we're doing, where we're going, how we're focused, and then bring in the other people. All this doesn't stop us from collaborating with other disciplines for all our grants and publications.

\section{DP: I am aware that all or most of the research studies that you and the other members of GRISIM conduct are interdisciplinary, but GRISIM focuses on nursing interventions.}

SC: Correct. GRISIM researchers are conducting research projects with others - for instance, projects in pain or cardiac care with other people, like physicians and other healthcare workers, because a research project often goes with a specific clientele. In that way, those specific projects are interdisciplinary. But GRISIM is about developing the science of nursing, which concentrates on nursing interventions. 


\section{DP: Is GRISIM evolving into a more interdisciplinary membership? Is it moving now towards nursing as the core, and then adding adjuncts from other disciplines?}

CJ: That's a little hard to predict. I still see nursing as the core, particularly in terms of the funding. We really want to use the funding to give nurses an opportunity to develop their careers. I think we'll probably keep GRISIM nursing focused and then bring in people as adjunct members. We have one member, Robin Cohen, who is not a nurse - but her appointment is in palliative care and nursing - and she supervises $\mathrm{PhD}$ nursing students, even though she's not by discipline a nurse.

\section{DP: How did you arrive at that focus - how did it evolve?}

CJ: At the very beginning, we decided we wanted to do excellent and innovative nursing intervention research. One of our primary goals was to develop the knowledge of nursing intervention. A second goal was to train people. Nursing interventions are always evolving and changing, just as conditions that people live with change as new medical treatments are developed, and so forth. So we need to train the next group to follow up on what we've done before.

\section{DP: You've talked about students a lot. What role do graduate students play in GRISIM?}

SC: Well, in a sense, they're our raison d'être. They're the next generation, and they need to be strong if the discipline of nursing is going to make its unique contribution. We've really got to invest a lot in the students. They participate on the teams; some of them are very key players on the team. They also, of course, participate in the regular seminars. We do whatever we can to help them and to make them feel connected to a community. Because $\mathrm{PhD}$ programs tend not to be particularly big, this gives them an opportunity to have an identity as a group of nursing researchers, so they aren't just with the clinicians when they're collecting data, or they're not epidemiology students when they're in their classes, or something like that. We're giving them a community and an identity, and opportunities to be a lot stronger than those in past generations.

\section{DP: What advantage do you think that students who have been associated with GRISIM will have when they're graduated? How would you expect them to advance careerwise relative to students who haven't had this experience?}

CJ: In a concrete way, they can say they've had peer-reviewed funding and have participated on a team to get their work published. We've encouraged all the teams to let the students lead some projects in which they will be the first authors. They're also going to get through the program sooner because they've been funded. In less measurable but still important ways, they gain a sense of community - that sense of existing in or participating in a group where there is a give and take of ideas, where there is criticism in an open and constructive way. There are 
senior researchers present, and their work is criticized by the group, including the students, so they understand what being a peer in a research group means.

SC: The sense of community is particularly important because often after classes in a $\mathrm{PhD}$ or master's program, students were left alone with their own research project. They didn't have peers with whom they could share their work. It's often not easy to conduct a research project, and if they have difficulties, like trying to recruit patients or other issues, they now have people to reassure them that it's not unusual, so they are feeling supported.

DP: The current environment for research in Canada has become quite problematic with the very limited additional funding going into CIHR, in particular. Have you experienced that, or does GRISIM help you manage in that constrained environment?

SC: We think one of the reasons our researchers are successful in funding competitions is that they have been able to do a pilot project that produced preliminary results. It's a really big plus for a lot of us in the beginning to get that new grant, the first grant.

CJ: Everybody from GRISIM who submitted a proposal to CIHR in this last round was funded. That's about six people who were either principal investigators or co-investigators. I agree with Sylvie that the pilots ensure the concreteness of having data. And to be funded by GRISIM, researchers have gone into a competition, not as competitive as CIHR, but nevertheless it's peer reviewed. We have a process of scientific evaluation, so they get feedback from that review which they incorporate into their pilot project. The other thing is that they've had the opportunity to present not only the formal evaluation from the scientific evaluation committee; we also encourage people to present their projects in seminars here and have others critique it. We have a statistician on staff, so the statistics part is going to be stronger because we have that expertise. We have editors, too. That's the other thing - that people are turning out more manuscripts. Many of the faculty from the University of Montreal do have not English as their first written language, so it's more difficult for them to get published in English journals. They use the editor and get published, so they look stronger going into the grant [application].

\section{DP: All research units are under pressure to demonstrate their value and are grappling with the question of the appropriate measurement to reflect that value. Can you talk about how you struggled with this, and the terms in which you report - the return on investment for GRISIM? \\ CJ: Well, the usual grants and publications are our primary benchmarks, because that's what everybody else uses. But to be more specific, we are also talking about}


which journals we are publishing in. We've identified the journals we want to publish in out of this teamwork, and we're hoping to have things submitted before the end of the summer. So it's not just adding up how many people had X number of publications, to come up with a number. We're going switch that metric a little bit from the traditional. Where we once would have said we have 20 members and they each published six articles this year to give us 120 articles, we're now going to talk more about how we worked together on one. There is a synergy that we've aimed for so that the authors are from both sides of the mountain. The second thing we're going to talk about is the quality of the articles. As we mentioned earlier, the science of nursing intervention research is going to be a unique metric for us. I think we can show we're making this unique contribution.

Of course, we will also track the numbers of pilot projects we funded that were later funded by granting agencies. The other metric we will use is collaboration - for instance, how many students have committee members from both sites on their committee?

CJ: In the short term, we are focusing on the science and conduct of nursing intervention research; we are not yet transferring the results of projects into clinical practice. But in two or three years we will have results and be ready to move from clinical trials into practice. One of the teams is looking at knowledge translation and nursing intervention research and how these can be included from the conception of a project through development and implementation. That is farther down the road. As Sylvie says, we don't have results yet, but the team is looking at how we could be more integrated all along with our projects.

\section{DP: Are there some things you want to tell readers that I haven't asked you?}

SC: The geography issue is always there. People have to do their work within GRISIM and also within their own specialty. We talked about this last year, and it's still an issue for the future, because it will always be that way, and there is no way we can remove people from their milieu.

We have resorted to things like videoconferencing and computer software to allow for presentations with interactions from people [at the three sites]. When I have my team meetings, sometimes the people on the team want to be in their own offices and meet from there and don't want to come over to GRISIM, so it's tough to know what the answer is. If you have the unit at one university, then the people from the other university have to travel - so this way everybody suffers equally. It is a problem. We've also fantasized about having a mini bus run among the three sites, and people can hop on and off if they wish. 
I think for some of the people in some of the sites it'll [soon] be easier to go between the university and the GRISIM site, but I don't think that's going to take away the issue of competition between the University of Montreal and McGill. Therefore, you need to have "neutral" territory. As you know, the compromise here is that GRISIM is geographically close to McGill but it's actually just across the street, and the building belongs to the University of Montreal teaching hospital.

DP: GRISIM is an interesting and unique new initiative in nursing research. It is trying to overcome the challenges of working across two universities, two locations, two cultures and two languages to advance the science and outcomes of nursing intervention research. Unlike many research units, GRISIM is well funded from a number of sources but it is under considerable pressure to produce research results. The emphasis on graduate students in nursing and an exclusively nursing membership to date separate it from other research units led by nurses. It will be interesting to watch it and learn from it as it evolves over the next several years.

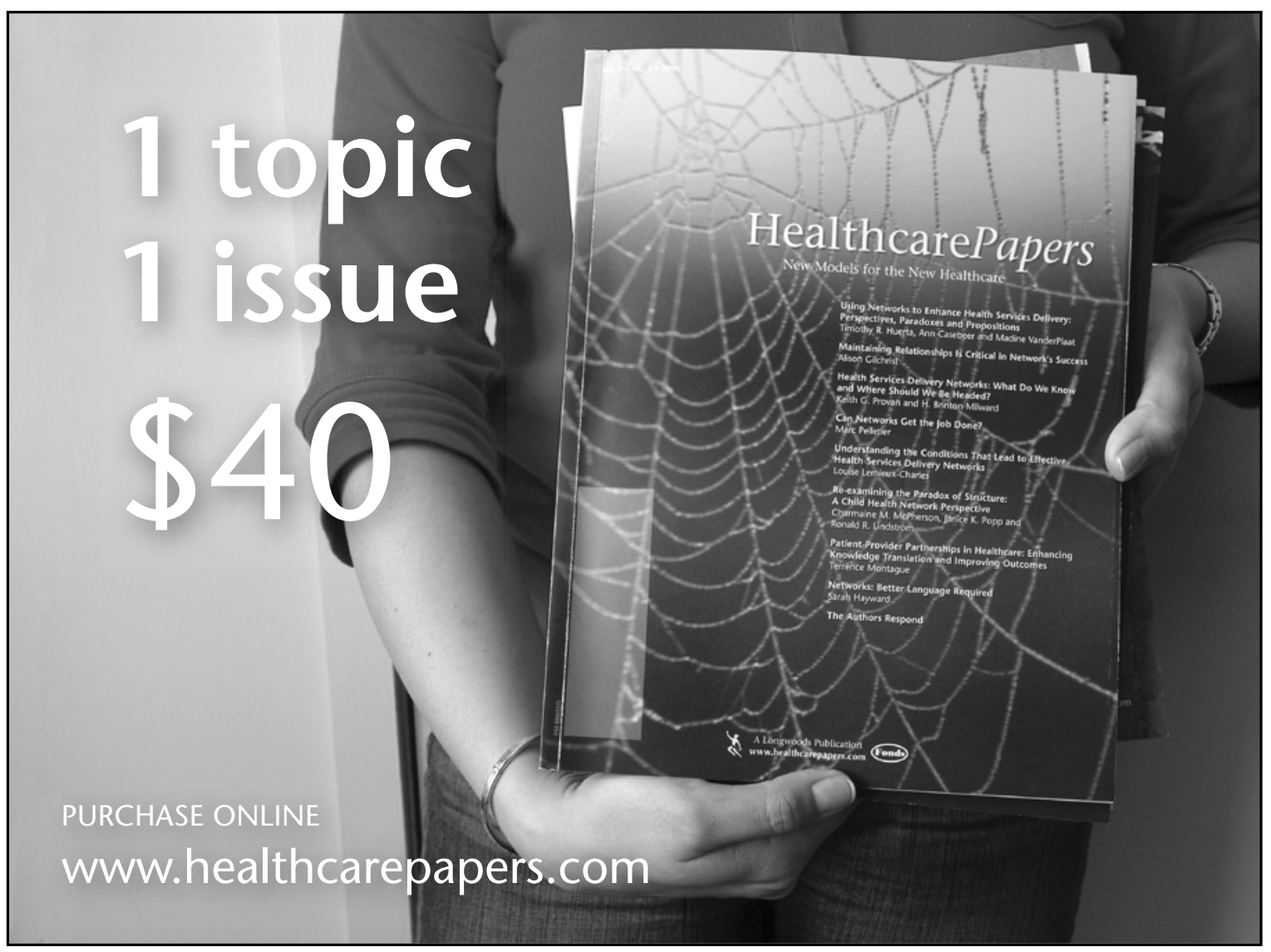

